\title{
Distribution and homogeneity of petroleum hydrocarbon in Jiaozhou Bay
}

\author{
Dongfang Yang1, 2, 4, a, Fengyou Wang1, 2, Sixi Zhu1, 2, Xiaoli \\ Zhao1, 2 and Jiaolian Luo3 \\ 1Research Center for Karst Wetland Ecology, Guizhou Minzu University, \\ Guiyang 550025, China; \\ 2College of Chemistry and Environmental Science, Guizhou Minzu \\ University, Guiyang 550025, China; \\ 3College of Information Engineering, Guizhou Minzu University, \\ Guiyang 550025, China; \\ 4North China Sea Environmental Monitoring Center, SOA, Qingdao \\ 266033, China \\ adfyang_dfyang@126.com
}

\begin{abstract}
Based on investigation dada on petroleum hydrocarbon (PHC) in April, June, Juny and October 1982 in Jiaozhou Bay, this paper analyzed the content, distribution and seasonal variations of PHC. Results showed that PHC contents in April, June, July and October in surface waters ranged from 0.03-0.07 mg.L-1, 0.05-0.10 mg.L-1,0.04-0.07 mg.L-1 and 0.03-0.04 mg.L-1, respectively, and were meeting Grade II and III in National Sea Water Quality Standard (GB 3097-1997), and were generally decreasing with time within the year. For spatial distribution, the ranges of PHC contents in April, July and October were 0.02 mg.L-1, 0.03 mg.L-1 and $0.01 \mathrm{mg} . \mathrm{L}-1$, respectively, indicated that the distributions of PHC in the southwest were tended to be homogenous. The results confirm that tide and current are stirring and transporting all of the materials in the ocean, resulting in the homogous distributions of the contents of various materials in waters.
\end{abstract}

Keywords: Petroleum hydrocarbon; Content; Distribution; Homogenity; Jiaozhou Bay

\section{Introduction}

Due to the rapid increase of ocean development such as ocean transportation, offshore oil exploitation, offshore oil delivery etc., PHC pollution especially oil spill had been serious problem [1]. Therefore, understanding the pollution level and seasonal variations of PHC is essential to marine environment protection and the maintaining of sustainable development of marine economy.

Jiaozhou Bay is located in Shandong province, eastern China, and had been polluted by PHC [2-3]. In order to provide basis for pollution control and 
environmental remediation, this paper analyzed the content, distribution seasonal variation of PHC based on investigation dada on PHC in April, June, July and October 1982 in Jiaozhou Bay surface waters.

\section{Material and method}

Jiaozhou Bay $\left(35^{\circ} 55^{\prime}-36^{\circ} 18^{\prime} \mathrm{N}, 120^{\circ} 04^{\prime}-120^{\circ} 23^{\prime} \mathrm{E}\right)$ is a semi-closed bay located in the south of Shandong Province, eastern China (Fig. 1). The total area, average water depth and bay mouth depth $390 \mathrm{~km} 2,7 \mathrm{~m}$ and $3 \mathrm{~km}$, respectively. The bay has more than ten inflow rivers, including Haibo Rriver, Licun Rriver, Baisha Rriver, Dagu Rriver, and Loushan Rriver etc., all of which have seasonal features, and are playing roles of input channels of various pollutants [4].

The data was provided by North China Sea Environmental Monitoring Center. The survey was conducted in April, June, July and October 1982. There were 5 monitoring sites in April, namely 083, 084, 121, 122 and 123 in the investigations in April, July and October. While for the investigation in June, there were 4 monitoring sites namely $\mathrm{H} 37, \mathrm{H} 39, \mathrm{H} 40$ and $\mathrm{H} 41$, respectively. $\mathrm{PHC}$ was monitored follow by National Specification for Marine Monitoring [5]. 


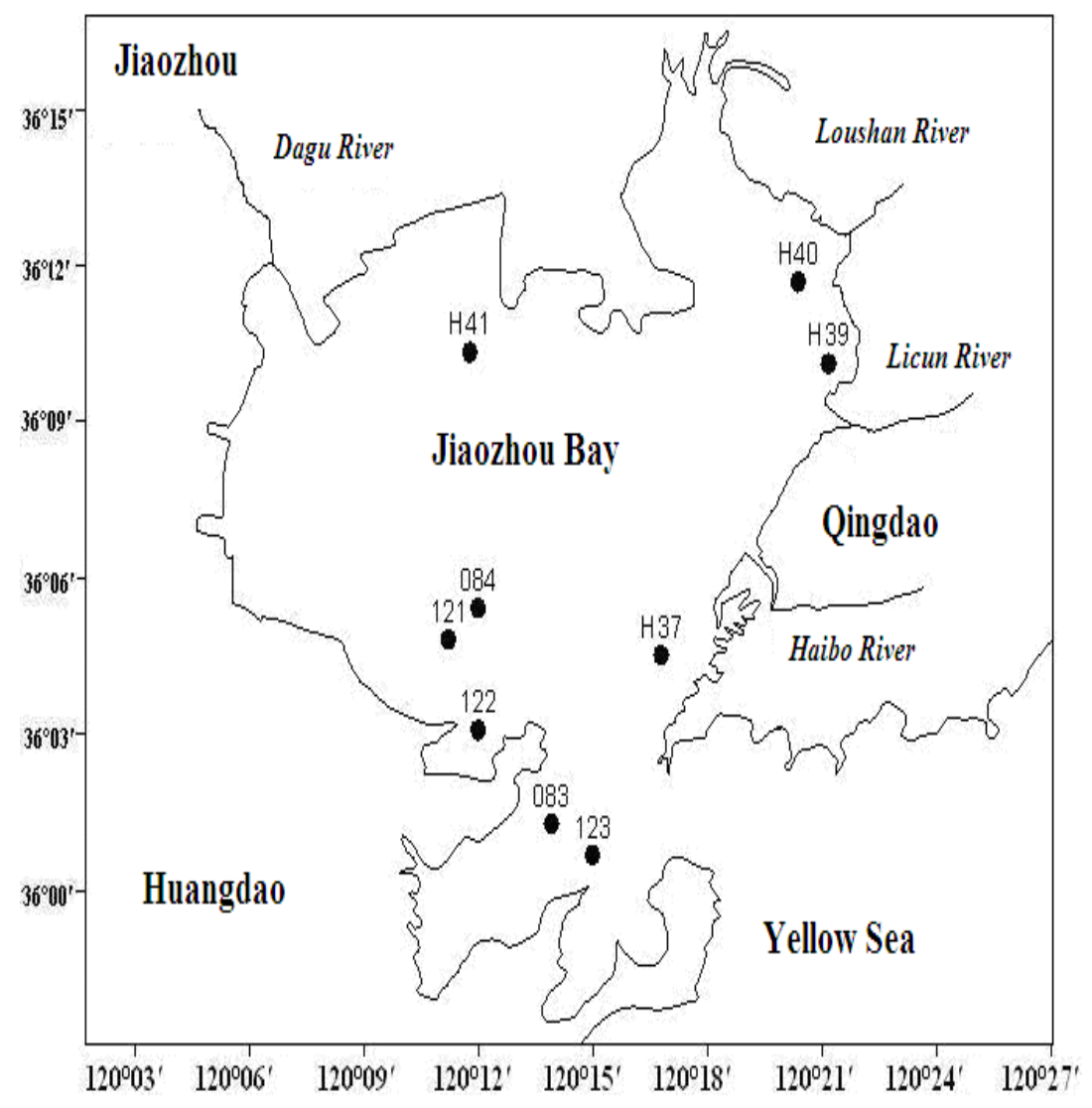

Fig.1 Geographic location and monitoring sites in Jiaozhou Bay

\section{Results and discussion}

Contents. The content of PHC in April, June, July and October in surface waters ranged from $0.03-0.07 \mathrm{mg} . \mathrm{L}^{-1}, 0.05-0.10 \mathrm{mg} . \mathrm{L}^{-1}, 0.04-0.07 \mathrm{mg} . \mathrm{L}^{-1}$ and $0.03-0.04$ mg. $\mathrm{L}^{-1}$, respectively. PHC contents were meeting Grade II $\left(0.05 \mathrm{mg} . \mathrm{L}^{-1}\right)$ and III (0.30 mg.. $\mathrm{L}^{-1}$ ) in National Sea Water Quality Standard (GB 3097-1997), indicating that Jiaozhou Bay was mildly polluted by PHC in 1982 . We defined April, June and July, and October as spring, summer and autumn, respectively. It was obviously that water quality based on PHC was generally decreasing with time within the year.

Distributions. In April, high value occurred in Site 122 in southwest of the bay, forming a series of semi-concentric circles, which were decreasing from the high value center to the center of the bay (Fig. 2a). In June, high value occurred in 
Site H40 in the mouth of Loushan River, forming a series of semi-concentric circles, which were also decreasing from the high value center to the bay mouth (Fig. 2b). In July, high value occurred in Site 121 in southwest of the bay, forming a series of semi-concentric circles, which were also decreasing from the high value center to the center of the bay (Fig. 2c). In October, high value occurred in coastal waters in southwest of the bay, and were also forming a series of semi-concentric circles, which were also decreasing from the high value center to the center of the bay and the bay mouth (Fig. 2d).
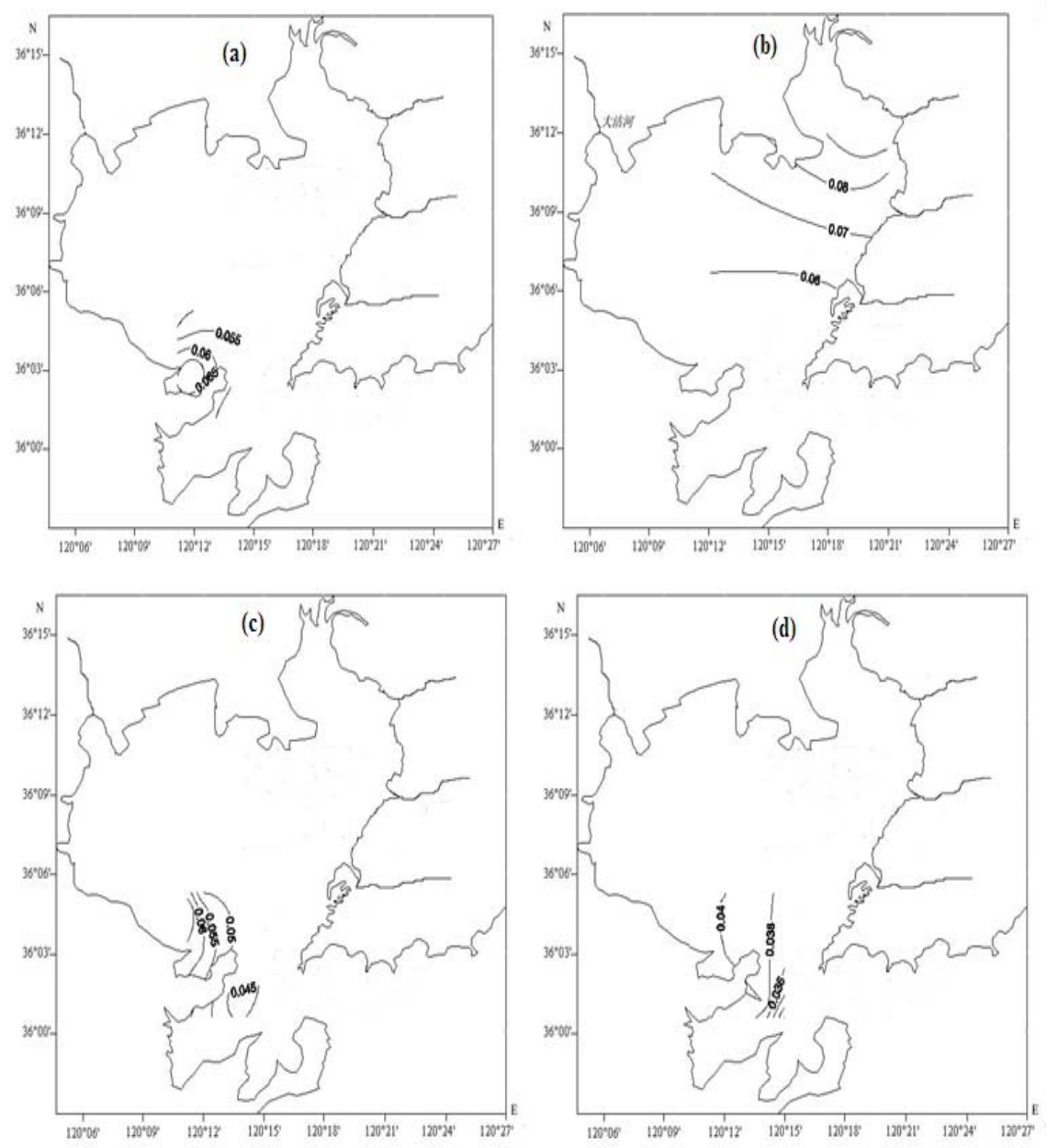

Fig.2 Distributions of PHC contents in a) April, b) June, c) July and d) October 1982 in surface waters in Jiaozhou Bay/mg.L $\mathrm{L}^{-1}$ 
Homogeneity. By means of the disturbance of tide and current, pollutants including PHC were continually transported and mixed in waters. The monitoring sites in April, July and October were located in southwest of the bay, in where there was no major inflow rivers. The ranges of PHC contents in April, July and October were $0.02 \mathrm{mg} . \mathrm{L}-1,0.03 \mathrm{mg} . \mathrm{L}-1$ and $0.01 \mathrm{mg} . \mathrm{L}-1$, respectively, indicated that the distributions of PHC in the southwest were tended to be homogenous. The monitoring sites in April, July and October were located in northeast of the bay, in where there were major inflow rivers such as Loushan River, Licun River etc. Hence, the distributions of PHC were inhomogenous yet were decreasing with the flow directions of the major rivers, due to stream discharge was one of the major sources of PHC in this bay. As has been pointed out by Yang et al. (2011), tide and current are stirring and transporting all of the materials in the ocean, resulting in the homogous distributions of the contents of various materials in waters [6].

\section{Conclusion}

The contents of PHC in April, June, July and October in surface waters indicated that Jiaozhou Bay was mildly polluted by PHC in 1982, and water quality based on PHC were generally decreasing with time within the year. The ranges of PHC contents indicated that the distributions of PHC in the southwest were tended to be homogenous. The results confirm that tide and current are stirring and transporting all of the materials in the ocean, resulting in the homogous distributions of the contents of various materials in waters.

\section{Acknowledgement}

This study was supported by Education Ministry's New Century Excellent Talents Supporting Plan (NCET-12-0659), Project of Outstanding Technological Educators of Governor of Guizhou ([2012]71), Project of Low Carbon Technology Plan of Guiyang (2012205]), Project of Science and Technology Foundation of Guiyang (LKM[2012]05), and Special Research Projects of High Level Talents of Guizhou Province (TZJF-2011-44).

\section{References}

[1] Minzhi Guo and Naihe Wang: Gas Storage and Transportation, Vol. 27(2008), p. 34-39. (in Chinese)

[2] Dongfang Yang, Youchi Zhang, Jie Zou, Qing Zhou and Hailing Yang: Open Journal of Marine Science, Vol. 2(2011), p.108-112.

[3] Dongfang Yang, Peiyan Sun, Chen Chen, Hongyan Bai and Qing Zhou: Coastal Engineering, Vol. 32 (2013), p. 60- 72. (in Chinese)

[4] Dongfang Yang, Yu Chen, Zhenhui Gao, Jing Zhang and Fan Wang: Chin. J. OceanoL. LimnoL., Vol. 23(2005), p. 72-90. 
[5] China's State Oceanic Administration: The specification for marine monitoring (Ocean Press, Beijiang 1991), p.1-300. (in Chinese)

[6] Dongfang Yang, Ziru Ding, Lin Zheng, Zhiguo Bu and Qiang Shi: Coastal Engineering, Vol. 30 (2011), p. 66- 74. (in Chinese) 